\title{
Patent Licensing in a Leadership Structure
}

\author{
By \\ Tarun Kabiraj \\ Indian Statistical Institute, Kolkata, India
}

(May 2002)

\begin{abstract}
This paper studies the question of optimal licensing contract in a leadership structure when the patent holder is a non-producer. We assume that the size of the innovation is exogenous and the patent holder has three alternative licensing strategies, viz., fee, royalty and auction. We show that when the innovation is small, royalty dominates other contracts. But for larger innovations while fee dominates royalty, auction is the equilibrium decision. Depending on the size of the innovation the license is given either to leader or to follower or to both. Hence identity of the licensee becomes an important variable.
\end{abstract}

Key words: Leadership structure, process innovation, fee licensing, royalty licensing, auctioning. JEL classifications: D45, L13.

Correspondence to: Tarun Kabiraj, Economic Research Unit, Indian Statistical Institute, 203 B. T. Road, Kolkata - 700108, India.

E-mail: tarunkabiraj@hotmail.com; Fax: 91335778893 


\section{Introduction}

An inventor while investing in R\&D expects a return on its investment. Possibility of technology transfer increases its inventive incentives. One important issue in the literature of technology transfer is to study the question of optimal licensing contract from the perspective of the inventor or innovator. Broadly, there are three types of licensing contracts discussed in the literature, viz., auction, fee licensing and royalty licensing. However, all options may not always be equally available to the innovator. For instance, if imitation is easy and patent protection is imperfect, writing a royalty contract is often difficult. ${ }^{1}$ On the other hand, technology transfer through auctioning is much less visible than other modes. There are some scattered evidences on the number of licensing contracts signed. For instance, the survey of firms by Rostoker (1984) shows that 39\% of cases have royalty licensing alone, 13\% have fee licensing alone, and $46 \%$ of cases have fee plus royalty contracts. To the study of the technology licensing contracts between Indian and foreign firms, Alam (1985) observes that lower royalty rates are associated with higher lump sum payments by the transferee. ${ }^{2}$

What will be the optimal licensing contract from the perspective of the patent holder? It really depends on a number of factors. ${ }^{3}$ Based on the assumptions of the model, the optimal decision will be royalty licensing, fee licensing or auction. ${ }^{4}$ In the present paper we assume that the patent holder is a non-producer and the product market has leadership structure with one leader and one follower competing in quantities. Also there is no informational problem, and imitation of the licensed technology is not possible. The patent holder's problem then is to decide which contract is to be given and to whom.

A few comments on the assumption of the product market structure are in order. Theoretically speaking, what will be the structure of the product market is an assumption of the model builder. In the literature the product market is assumed to be monopoly, competitive or simultaneous move oligopoly. No work so far has considered the case of a leadership structure. ${ }^{5}$ This paper is an attempt to fill up this gap. Moreover, in the real world there are a number of products the markets for which can be approximated as the leadership structures. Hence the model has also practical significance. With the assumption of the Stackelberg market

\footnotetext{
${ }^{1}$ See Shapiro (1985) and Katz and Shapiro (1985) for an analysis on this issue.

${ }^{2}$ See also a host of case studies available in the Economic and Political Weekly, Special Number, 1985.

${ }^{3}$ The important factors are : whether the inventing firm is a non-producer or a competitor in the same product market, whether the product market is competitive, monopoly or oligopoly, whether there is price competition or quantity competition, whether products are homogenous or differentiable, whether imitation is easy or difficult and patent protection is enforceable or imperfect, whether government puts restrictions on the payment structure or not, whether quality of the technology also figures in the contract, whether there is any informational problem, and whether innovations are large or small, etc.

${ }^{4}$ In this paper we shall not discuss the possibility of a mixture of the licensing strategies like fee plus royalty, etc.

${ }^{5}$ One exception is the work by Kabiraj (2002). It assumes that the patent holder is a competitor in the same product market. Then it studies welfare implications of the different licensing policies. In particular, the paper examines whether leader's innovation is socially more valuable than follower's.
} 
structure we derive some results that are distinctly different from the existing ones. One may further note that in a leadership structure even if the competitors have identical production technologies, a move advantage (or disadvantage) makes the firms asymmetric. Then the identity of a potential licensee becomes an important consideration to the patent holder. In a simultaneous move game it obviously does not play any role. Below we briefly outline the literature so that we can pinpoint our contributions.

The literature starts with the contribution of Arrow (1962). It discusses technology transfer by means of a royalty and shows that the patent holder derives a larger payoff from its transfer to a competitive firm than to a monopoly. Licensing in a competitive industry by means of both a fee and a royalty is discussed in Kamien and Tauman (1984). These models however cannot capture the strategic interaction of the firms, which is the hallmark of an oligopoly industry. Hence a series of articles have come out in the literature recognizing this strategic interaction. A nice survey of this literature can be found in Kamien (1992).

There are a number of articles that assume the patent holder to be a non-producer, an outsider to the product market. One important contribution is by Kamien and Tauman (1986). Here the patent holder transfers its technology to an oligopoly by means of a fee or a royalty when the product market is Cournot or Bertrand with homogeneous goods. It shows that licensing by means of a fixed fee is superior to licensing by means of a royalty for both the inventor and the consumers. On the other hand, Katz and Shapiro (1986) have studied licensing by means of an auction. Kamien et al. (1992) have extended these works to the class of a more general demand function and considered all three licensing strategies. Their paper shows that licensing by means of a royalty is inferior to other modes, and auction generally dominates fee licensing. Muto (1993) has a model of price competition with differentiated products. It portrays situations when royalty licensing dominates other forms of licensing.

On the other hand, Katz and Shapiro (1985), Rockett (1990) and Wang (1998) model the case when the patent holder is directly a competitor in the product market. Katz and Shapiro (1985) study innovation incentives in the presence of the licensing opportunities and assume fee contract with the presumption that in the presence of imitation writing a royalty contract will be difficult. Rockett (1990) provides a more general structure where quality of the licensed technology is also negotiated. Finally, Wang (1998) has compared the licensor's payoffs under royalty and fee contracts and shows that royalty contracts strictly dominate fee contracts if the innovation is non-drastic.

In the present paper the patent holder is an outsider and the product market has leadership structure. The patent holder has three alternative licensing strategies, viz., fee, royalty and auction. In between fee and royalty contracts, royalty contract is optimal if the innovation size is quite small, and in that case transfer to both firms (leader and follower) will occur; otherwise fee contract is the equilibrium decision. In particular, if the innovation is of the intermediate level, fee licensing to leader only is optimal, and for a larger 
innovation, fee licensing to follower will occur. Thus not only licensee's identity becomes an important consideration, but contrary to Kamien and Tauman (1986), royalty licensing can be an equilibrium decision. When all the licensing strategies are available, again royalty licensing to both figures in equilibrium for small innovations, and for all other cases auction dominates other modes. However, if the innovation is non-drastic, transfer to leader is optimal.

Some points may be noted. First, transfer to both firms under fee licensing is never optimal. Second, in Kamien et al. (1992) royalty is inferior to other modes of transfer. In contrary, in our paper royalty can be an equilibrium decision for low innovations. In Kamien and Tauman (2002) for non-drastic innovation royalty is superior to fee, but in our case both for drastic and non-drastic (but not too small) innovations fee dominates royalty. In the literature licensing decision is non-trivial only when the innovation is non-drastic, but in our paper when an innovation is drastic, knowing the identity of the licensee becomes crucially important. On the other hand, as in Kamien et al. (1992), auction is the optimal decision of the patentee when the innovation is not too small.

The plan of the paper is the following. In the second section we provide the model and discuss the three licensing strategies in three consecutive subsections. The third section deals with the question of an optimal licensing strategy from the viewpoint of the patent holder. The fourth section is a conclusion. Finally, an appendix is added so as to facilitate the derivations.

\section{Model:}

We consider a three-firm structure with one inventing but non-producing firm and two other producing but non-inventing firms. The product market is characterized by Stackelberg structure, with firm 1 as leader and firm 2 follower. The market demand is linear for a homogeneous product and is given by the equation

$$
P=a-Q=a-\left(q_{1}+q_{2}\right)
$$

where $P$ is the price of the product and $q_{i}$ is the supply of the i-th firm, $i=1,2$. Initially, producing firms are identical, and each has a constant unit cost of production $c, 0<c<a$. Hence, their initial payoffs are, respectively

$$
\pi_{1}^{0}=\frac{(a-c)^{2}}{8} \text { and } \pi_{2}^{0}=\frac{(a-c)^{2}}{16} .
$$

Now assume that the inventing firm comes up with a patent of a cost-reducing innovation; if it is used in production, it will result in a reduction of unit cost to $c-\varepsilon, 0<\varepsilon \leq c$. Therefore, $\varepsilon$ is the extent of unit 
cost reduction, and it can be interpreted as the size of the innovation. We further assume that $\varepsilon$ is exogenous in the model. ${ }^{6}$

Given the size of the invention, the patent holder will now decide its optimal licensing strategy, that is, the terms of the licensing contract it will offer to a licensee. Although the competing firms have initially the same technology, but they differ in respect of their moves. This has different implications for the patent holder. Hence the patent holder will also decide whether to license its technology to leader only or to follower only or to both.

We discuss three alternative licensing strategies, viz., fee licensing, royalty licensing and auctioning (i.e., licensing by auction). Under fee licensing, the patent holder licenses its technology to the licensee(s) against a fixed fee; under royalty contract it decides the royalty rate optimally, that is the royalty per unit of output produced by the licensee(s) using the innovation. Finally, under auctioning, the innovator transfers its technology to the highest bidder (by means of the first-price auction). In the following subsections we estimate the payoffs of the innovator under different licensing contracts.

\subsection{Fee Licensing}

Under this strategy the patent holder first decides to whom to license the innovation, and then it gives the contract $\left(F_{x}, x ; \varepsilon\right)$. This states that the patent holder offers the technology $\varepsilon$ against a fee to $x$, where $x=1$ (leader only), 2 (follower only), 3 (both), and if the contract is accepted by the licensee(s), the patent holder derives a payoff, $\mathrm{F}_{\mathrm{x}}$ as fixed fee. We can then derive (see Appendix A)

$$
\begin{aligned}
\mathrm{F}_{1} & =\frac{(a-c+2 \varepsilon)^{2}}{8}-\frac{(a-c)^{2}}{8} \quad \text { if } \varepsilon<(a-c) / 2 \\
& =\varepsilon(a-c)-\frac{(a-c)^{2}}{8} \quad \text { if }(a-c) / 2 \leq \varepsilon<(a-c) \\
& =\frac{(a-c+\varepsilon)^{2}}{4}-\frac{(a-c)^{2}}{8} \quad \text { if } \varepsilon \geq(a-c) \\
\mathrm{F}_{2} & =\frac{(a-c+3 \varepsilon)^{2}}{16}-\frac{(a-c)^{2}}{16} \quad \text { if } \varepsilon<(a-c) \\
& =\frac{(a-c+\varepsilon)^{2}}{4}-\frac{(a-c)^{2}}{16} \quad \text { if } \varepsilon \geq(a-c)
\end{aligned}
$$

and

\footnotetext{
${ }^{6}$ We shall not model the issue of innovation explicitly in the paper, but our model can explain the incentive of such an innovation.
} 


$$
\mathrm{F}_{3}=\frac{3}{16}\left[\varepsilon^{2}+2 \varepsilon(a-c)\right] \quad \text { for } 0<\varepsilon \leq c
$$

Then comparing the expressions of $\mathrm{F}_{1}, F_{2}$ and $F_{3}$, we shall get the following. ${ }^{7}$

$$
\exists \varepsilon^{*},(a-c) / 2<\varepsilon^{*}<(a-c), \text { such that } F_{1}>,<F_{2} \Leftrightarrow \varepsilon<,>\varepsilon^{*} \text { and } \mathrm{F}_{3}<\max \left\{F_{1}, F_{2}\right\}
$$

Hence we have the following proposition.

Proposition 1: If to the patent holder only fee licensing strategy is available, it will transfer to firm 1 only if the innovation size is relatively smaller, and to firm 2 only if it is larger; transfer to both firms will never occur.

Intuition of the result is the following. Leader has first mover advantage. This generates a larger gross profit to the leader from the licensed technology if it is non-drastic (i.e., $\varepsilon<a-\mathrm{c}$ ), and gross profit is same for both leader and follower when the technology is drastic (i.e, $\varepsilon \geq \mathrm{a}-\mathrm{c}$ ). But leader has at the same time larger reservation payoff.. Hence the patent holder derives a larger payoff from the transfer of its technology to leader (follower) if the innovation is relatively small (large). Further, the critical $\varepsilon^{*}$ occurs at a level before the technology becomes drastic. On the other hand, if both firms are transferred, while the efficiency effect increases industry profit, but competition does not allow the industry payoff to increase large enough.

\subsection{Royalty Licensing}

In this case the patent holder gives the contract $\left(r_{x}, x ; \varepsilon\right)$, i.e., it charges a royalty rate $r_{x}$ for transferring its innovation $\varepsilon$ to $x, x=1,2,3 .{ }^{8}$ Correspondingly, its optimal royalty incomes $R_{x}$ are derived as (see Appendix B):

7 We must have $\mathrm{F}_{1}>F_{2}$ for $\varepsilon<(\mathrm{a}-\mathrm{c}) / 2$ and $\mathrm{F}_{1}<F_{2}$ for $\varepsilon \geq(\mathrm{a}-\mathrm{c})$. In our case $\varepsilon^{*}=\left(5+7^{1 / 2}\right)(a-c)=0.8495(a-c)$ (approximately).

${ }^{8}$ When the patent holder transfers its technology to both firms, it chooses the royalty rates optimally, but it turns out that the optimal rate is same for both firms. 


$$
\begin{array}{rlrl}
\mathrm{R}_{1} & =\varepsilon \frac{(a-c)}{2} & & \text { if } \varepsilon<(a-c) / 2 \\
& =\frac{(a-c+2 \varepsilon)^{2}}{16} & \text { if } \varepsilon \geq(a-c) / 2 \\
\mathrm{R}_{2} & =\varepsilon \frac{(a-c)}{4} & \text { if } \varepsilon<(a-c) / 3 \\
& =\frac{(a-c+3 \varepsilon)^{2}}{48} & \text { if } \varepsilon \geq(a-c) / 3
\end{array}
$$

and

$$
\begin{aligned}
\mathrm{R}_{3} & =\frac{3 \varepsilon(a-c)}{4} \quad \text { if } \varepsilon<(a-c) \\
& =\frac{3(a-c+\varepsilon)^{2}}{16} \quad \text { if } \varepsilon \geq(a-c)
\end{aligned}
$$

Comparing these values we shall get

$$
R_{1}>R_{2} \forall \varepsilon, \text { and } R_{3}>R_{1} \text { for } \varepsilon<a-c \text {. }
$$

Moreover, if $c>\hat{c}$,

$$
\exists \hat{\varepsilon}, a-c<\hat{\varepsilon}<c \text { such that } R_{3}>\text {,or }<R_{1} \Leftrightarrow \varepsilon<, \text { or }>\hat{\varepsilon} .9
$$

Therefore,

$$
R_{1}>R_{3} \text { iff } c>\hat{c} \text { and } \varepsilon>\hat{\varepsilon} \text {; otherwise } R_{3}>R_{1} .
$$

Immediately we have the following result.

Proposition 2: When only royalty licensing strategy is available to the patent holder, if to transfer to one firm only, it is optimal to transfer to leader. If at the same time transfer to both firms is also allowed, the optimal strategy is to transfer to both firms provided that the initial unit cost of production is not very large. When the unit cost is quite large, transfer to leader only will be the optimal strategy if and only if the innovation size is large enough.

${ }^{9}$ Consider $\varepsilon \geq \mathrm{a}-\mathrm{c}$. Then, $R_{3}>R_{1}$ iff $\Delta(\varepsilon)=\varepsilon^{2}-2 \varepsilon(a-c)-2(a-c)^{2}<0$. Now $\Delta(\varepsilon)$ is strictly convex in $\varepsilon$, and it reaches minimum at $\varepsilon=a-c$, with $\Delta(a-c)<0$. Let $\Delta(\varepsilon)=0$ at $\hat{\varepsilon}$ for $\hat{\varepsilon}>a-c$ where $\hat{\varepsilon}=\left(1+3^{1 / 2}\right)(a-c)>a-c$. Then $\hat{\varepsilon}<c \Leftrightarrow c>\hat{c}=\left(\frac{1+3^{1 / 2}}{2+3^{1 / 2}}\right) a,$. 
A comparison between fee and royalty leads to the following proposition.

Proposition 3: If both fee and royalty licensing strategies are available to the patent holder, and if it is to license its technology to a single firm, the optimal strategy is fee licensing (i.e., $F_{i}>R_{i}$, for $i=1,2$ ), and if to transfer to both firms, royalty licensing becomes the optimal strategy (i.e., $R_{3}>F_{3}$ ).

\subsection{Auctioning}

Under the bidding game, the maximum that a producing firm can pay to the patent holder for the licensed technology of size $\varepsilon$ is its payoff when it gets the patent but the rival fails to get minus its payoff when the rival succeeds but it fails. So this is the maximum amount that a firm can spend on wining the patent of that technology. If $\Phi_{i}(\varepsilon)$ be the maximum price that the i-th firm is willing to pay ${ }^{10}$, then we have

$$
\begin{aligned}
\Phi_{1}(\varepsilon) & =\frac{(a-c+2 \varepsilon)^{2}}{8}-\frac{(a-c-\varepsilon)^{2}}{8} & & \text { if } \varepsilon<(a-c) / 2 \\
& =\varepsilon(a-c)-\frac{(a-c-\varepsilon)^{2}}{8} & & \text { if }(a-c) / 2 \leq \varepsilon<(a-c) \\
& =\frac{(a-c+\varepsilon)^{2}}{4}-0 & & \text { if } \varepsilon \geq(a-c)
\end{aligned}
$$

and

$$
\begin{array}{rlrl}
\Phi_{2}(\varepsilon) & =\frac{(a-c+3 \varepsilon)^{2}}{16}-\frac{(a-c-2 \varepsilon)^{2}}{16} \quad \text { if } \varepsilon<(a-c) / 2 \\
& =\frac{(a-c+3 \varepsilon)^{2}}{16}-0 \quad \text { if }(a-c) / 2 \leq \varepsilon<(a-c) \\
& =\frac{(a-c+\varepsilon)^{2}}{4}-0 & \text { if } \varepsilon \geq(a-c)
\end{array}
$$

Hence comparing, we have

$$
\begin{aligned}
& \Phi_{1}(\varepsilon)>\Phi_{2}(\varepsilon) \text { if } \varepsilon<a-c \\
& \Phi_{1}(\varepsilon)=\Phi_{2}(\varepsilon) \text { if } \varepsilon \geq a-c
\end{aligned}
$$

Thus if the innovation is non-drastic, firm 1 will preempt firm 2, and in case of drastic innovation, both firms will have same incentives to win the patent. Therefore, in equilibrium firm 2 will bid $B_{2}=\Phi_{2}(\varepsilon) \forall \varepsilon$, whereas firm 1 will bid $B_{1}$ where $B_{1}=B_{2}+$ a very small amount to win the bid in case of non-drastic innovation, and $B_{1}=B_{2}$ when the innovation is drastic. Hence by auctioning its

\footnotetext{
${ }^{10}$ Thus we have $\Phi_{1}(\varepsilon)=\pi_{1}^{1}(\varepsilon)-\pi_{1}^{f}(\varepsilon)$ and $\Phi_{2}(\varepsilon)=\pi_{2}^{\mathrm{f}}(\varepsilon)-\pi_{2}^{l}(\varepsilon)$ (see appendices for notations).
} 
technology, the patent holder is expecting a payoff $B$ where $B=B_{2}=\Phi_{2}(\varepsilon)$ (in the limiting sense), that is,

$$
\begin{aligned}
B(\varepsilon) & =\frac{(a-c+3 \varepsilon)^{2}}{16}-\frac{(a-c-2 \varepsilon)^{2}}{16} & & \text { if } \varepsilon<(a-c) / 2 \\
& =\frac{(a-c+3 \varepsilon)^{2}}{16}-0 & & \text { if }(a-c) / 2 \leq \varepsilon<(a-c) \\
& =\frac{(a-c+\varepsilon)^{2}}{4}-0 & & \text { if } \varepsilon \geq(a-c)
\end{aligned}
$$

Thus under auction strategy, leader will certainly get the licensed technology if the innovation is nondrastic, whereas in case of drastic innovation it gets the technology with one-half chance. This gives the following proposition.

Proposition 4: Under auction the leader will always outbid the follower and win the license if the innovation is non-drastic.

\section{Optimal Licensing Contracts}

In this section we assume that the patent holder has all the three licensing strategies available, and given the size of the innovation, it also decides optimally which firm is to be licensed.

First, consider the case when $\varepsilon<\frac{a-c}{2}$. Then under fee licensing, given (6), transfer to firm 1 is optimal. This yields a payoff to the patent holder equal to,

$$
F_{1}=\frac{(a-c+2 \varepsilon)^{2}}{8}-\frac{(a-c)^{2}}{8} .
$$

Under royalty licensing, given (10), it is optimal to transfer to both firms. The corresponding payoff of the patentee is:

$$
R_{3}=\frac{3 \varepsilon(a-c)}{4} .
$$

Finally, under auctioning, transfer to firm 1 is optimal. This yields a payoff to the patentee

$$
B=\frac{(a-c+3 \varepsilon)^{2}}{16}-\frac{(a-c-2 \varepsilon)^{2}}{16} \text {. }
$$

Comparing $F_{1}, R_{3}$ and $B$ above we shall get 


$$
\begin{array}{ll}
R_{3}>B>F_{1} & \text { if } \varepsilon \in[0,2(a-c) / 5) \\
B \geq R_{3}>F_{1} & \text { if } \varepsilon \in[2(a-c) / 5,(a-c) / 2)
\end{array}
$$

Next, consider the case $\frac{a-c}{2} \leq \varepsilon<a-c$. Then from (6) it follows that under fee licensing technology will be transferred to firm 1 or to firm 2 and thereby the patentee will receive a payoff $F_{1}$ or $F_{2}$ according as whether $\varepsilon<$, or $>\varepsilon^{*}$, but never to both firms. In this case,

$$
F_{1}=\varepsilon(a-c)-\frac{(a-c)^{2}}{8} \text { and } F_{2}=\frac{(a-c+3 \varepsilon)^{2}}{16}-\frac{(a-c)^{2}}{16} \text {. }
$$

Under royalty contract, on the other hand, license will be given to both firms (see (10)). This yields a payoff to the patentee $R_{3}=\frac{3 \varepsilon(a-c)}{4}$. The payoff of the patentee under auctioning (see (15)) is,

$$
B=\frac{(a-c+3 \varepsilon)^{2}}{16} .
$$

We can then easily check that

$$
\begin{aligned}
& B>F_{1}>R_{3} \quad \text { when } \varepsilon<\varepsilon^{*} \\
& B>F_{2}>R_{3} \quad \text { when } \varepsilon \geq \varepsilon^{*}
\end{aligned}
$$

that is, when $(a-c) / 2 \leq \varepsilon<a-c$, auction strategy strictly dominates other strategies.

Finally, consider the interval $(a-c) \leq \varepsilon<c$. From (6), the largest possible payoff of the patentee under fee licensing is

$$
F_{2}=\frac{(a-c+\varepsilon)^{2}}{4}-\frac{(a-c)^{2}}{16} .
$$

Under royalty licensing it follows from (11) that the maximum possible payoff of the patent holder will be

$$
\begin{aligned}
& R_{3}=\frac{3(a-c+\varepsilon)^{2}}{16} \text { if }(a-c) \leq \varepsilon<\hat{\varepsilon} \\
& \text { or, } R_{1}=\frac{(a-c+2 \varepsilon)^{2}}{16} \text { if } \hat{\varepsilon} \leq \varepsilon<c
\end{aligned}
$$

when $c>\hat{c}$; otherwise, it is $R_{3}$ as above. Then comparing for all possible cases we shall get, ${ }^{11}$

$$
B>F_{2} \text { and } B>\max \left\{R_{3}, R_{1}\right\}
$$


Summarizing the results of this section (see (16) through (18)) we can write the following proposition.

Proposition 5: When all licensing strategies (viz., fee licensing, royalty licensing and auction licensing) are available to the patent holder, its optimal strategy is to give a royalty contract to each competing firm (with a royalty rate, $r=\varepsilon$ ) if and only if the innovation size is quite small i.e., $\varepsilon<2(a-c) / 5$. For all $\varepsilon \geq 2(a-c) / 5$, auction strictly dominates all other licensing strategies. However, in this case transfer to leader will occur if the innovation is non-drastic; if the innovation is drastic, the patent holder auctions the technology to either leader or follower.

When the patent holder is to go for either fee or royalty licensing only, the optimal licensing strategy is summarized in the following proposition.

Proposition 6: Assume that the patent holder has only two alternative licensing strategies, viz., fee and royalty. Then its optimal strategy is to give (i) a royalty contract to both firms if the innovation size is quite small (i.e., $\varepsilon<2(-c) / 5$ ), (ii) a fee contract to leader when innovation is of the intermediate level (i.e., $2(-c) / 5 \leq \varepsilon<\varepsilon^{*}$ ), and (iii) a fee contract to follower when the innovation is large (i.e., $\varepsilon^{*} \leq \varepsilon<c$ ).

\section{Conclusion}

In this paper we discuss the question of optimal licensing contract from the perspective of the inventor when the product market has Stackelberg structure. The existing literature assumes the product market to be either competitive, monopoly or simultaneous-move oligopoly. Thus we fill up a gap in the theoretical literature. Given the fact that there are many products whose markets are close to the leadership structures, our model has practical significance as well. We have assumed that the patent holder is an outsider to the product market and it has three alternative licensing strategies, viz., fee, royalty and auction. We have shown that for a small innovation the optimal strategy is royalty licensing. While for relatively large innovations fee contract dominates royalty contract, but auction is the equilibrium decision. Given asymmetry of moves in a leadership structure, the decision of the optimal contract takes into account the identity of the potential licensees. This is quite clear from the fact that under fee licensing both firms will never be transferred, while under royalty contract, which turns out to be the equilibrium decision for small sized innovations, both firms will be licensed. On the other hand, in case of auction if the innovation is non-drastic, licensing to leader is optimal, and for drastic innovations, either leader or follower is licensed.

${ }^{11}$ We have $R_{3}>R_{1}, R_{2}$ when $c \leq \hat{c}$, and in this case we have $F_{2}>R_{3}$. When $c>\hat{c}$, if $\varepsilon<\hat{\varepsilon}$, then $F_{2}>R_{3}>R_{1}$, and when $c>\hat{c}$ and $\varepsilon \geq \hat{\varepsilon}$, we have $F_{2}>R_{1}>R_{3}$. 


\section{Appendix}

\section{Appendix A}

If the innovation $\varepsilon$ is transferred to leader (firm 1), its gross payoff (before fee is deducted) is

$$
\begin{aligned}
\pi_{1}^{l} & =\frac{(a-c+2 \varepsilon)^{2}}{8} & & \text { if } \varepsilon<(a-c) / 2 \\
& =\varepsilon(a-c) & & \text { if }(a-c) / 2 \leq \varepsilon<(a-c) \\
& =\frac{(a-c+\varepsilon)^{2}}{4} & & \text { if } \varepsilon \geq(a-c)
\end{aligned}
$$

while if the innovation is transferred to follower (firm 2), transferee's gross payoff is

$$
\begin{aligned}
\pi_{2}^{\mathrm{f}} & =\frac{(a-c+3 \varepsilon)^{2}}{16} \quad \text { if } \varepsilon<(a-c) \\
& =\frac{(a-c+\varepsilon)^{2}}{4} \quad \text { if } \varepsilon \geq(a-c)
\end{aligned}
$$

Then $F_{1}$ and $F_{2}$ are defined as

$$
F_{1}=\pi_{1}^{l}-\pi_{1}^{0} \text { and } F_{2}=\pi_{2}^{f}-\pi_{2}^{0}
$$

When the technology is transferred to both firms, their gross payoffs are

$$
\tilde{\pi}_{1}=(\mathrm{a}-\mathrm{c}+\varepsilon)^{2} / 8 \text { and } \tilde{\pi}_{2}=(a-c+\varepsilon)^{2} / 16
$$

Therefore,

$$
F_{3}=\left(\tilde{\pi}_{1}+\tilde{\pi}_{2}\right)-\left(\pi_{1}^{0}+\pi_{2}^{0}\right)
$$

\section{Appendix B}

If a royalty contract $r_{1}$ (per unit of output) is offered to firm 1, its output will be

$$
q_{1}^{l}=\frac{a-c}{2}+\left(\varepsilon-r_{1}\right)
$$

Then the optimal royalty $r_{1}^{*}$ is the solution to the problem

$$
\max _{r_{1}} r_{1} q_{1}^{l} \quad \text { s.t. } \quad r_{1} \leq \varepsilon
$$

This generates,

$$
\begin{aligned}
r_{1}^{*} & =\varepsilon & \text { if } & \varepsilon<(a-c) / 2 \\
& =\frac{a-c+2 \varepsilon}{4} & \text { if } & \varepsilon \geq(a-c) / 2
\end{aligned}
$$


Then,

$$
R_{1}=r_{1}^{*} q_{1}^{l}\left(r_{1}^{*}\right)
$$

Similarly, by giving the royalty contract to follower, the innovator is expecting a payoff,

$$
R_{2}=r_{2}^{*} q_{2}^{f}\left(r_{2}^{*}\right)
$$

where $r_{2}^{*}$ is the solution to the problem

$$
\max _{r_{2}} r_{2} q_{2}^{f} \quad \text { s.t. } \quad r_{2} \leq \varepsilon,
$$

with $q_{2}^{f}=\frac{a-c}{4}+\frac{3}{4}\left(\varepsilon-r_{2}\right)$. Hence,

$$
\begin{aligned}
& r_{2}^{*}=\varepsilon \quad \text { if } \varepsilon<(a-c) / 3 \\
& =\frac{a-c+3 \varepsilon}{6} \quad \text { if } \quad \varepsilon \geq(a-c) / 3
\end{aligned}
$$

When the technology is transferred to both firms under royalty contract $\left(r_{1}, r_{2}\right)$, the optimal royalty rates are the solution to the problem

$$
\max _{\left\{r_{1}, r_{2}\right\}} r_{1} q_{1}+\mathrm{r}_{2} \mathrm{q}_{2} \quad \text { s.t. } \quad r_{1}, r_{2} \leq \varepsilon
$$

where

$$
q_{1}=\frac{a-c+\varepsilon-2 r_{1}+r_{2}}{2} \text { and } q_{2}=\frac{a-c+\varepsilon+2 r_{1}-3 r_{2}}{4}
$$

This gives the optimal royalty rates

$$
\begin{aligned}
& \widetilde{r}=\widetilde{r}_{1}=\widetilde{r}_{2}=\varepsilon \quad \text { if } \varepsilon<a-c \\
& =\frac{a-c+\varepsilon}{2} \quad \text { if } \quad \varepsilon \geq a-c
\end{aligned}
$$

This generates a royalty income to the patent holder equal to

$$
R_{3}=\widetilde{r}_{1} q_{1}\left(\widetilde{r}_{1}\right)+\widetilde{r}_{2} q_{2}\left(\widetilde{r}_{2}\right)=\widetilde{r}\left(q_{1}(\widetilde{r})+q_{2}(\widetilde{r})\right)
$$




\section{References}

Alam, G., 1985, "India's technology policy and its influence on technology imports and technology development”, Economic and Political Weekly, Special Number (November), 2073-80.

Arrow, K., 1962, "Economic welfare and the allocation of resources for innovation", in Nelson, R.R., ed., The Rate and Direction of Inventive Activity, Princeton University Press.

Economic and Political Weekly, Special Number (November), 1985, Mumbai.

Kabiraj, T., 1992, "Technology Transfer In a Stackelberg Structure: Licensing Contracts and Welfare”, ERU Discussion Paper No. 2002/04, Indian Statistical Institute, Kolkata.

Kamien, M., 1992, "Patent licensing", in Aumann, R.J. and S. Hart, eds., Handbook of Game Theory with Economic Applications, Vol. 1, Ch. 11, 331-354, Elsevier Science Publishers, Amsterdam.

Kamien, M., S. Oren and Y. Tauman, 1992, “Optimal licensing of cost-reducing innovation”, Journal of Mathematical Economics 21, 483-508.

Kamien, M. and Y. Tauman, 1984, "The private value of a patent: A game theoretic analysis", Journal of Economics (Supplement) 4, 93-118.

Kamien, M. and Y. Tauman, 1986, "Fees versus royalties and the private value of a patent", Quarterly Journal of Economics 101, 471-491.

Kamien, M. and Y. Tauman, 2002, "Patent licensing: The inside story", The Manchester School 70, 7-15.

Katz, M. and C. Shapiro, 1985, "On the licensing of innovation”, Rand Journal of Economics 16, 504-519.

Katz, M. and C. Shapiro, 1986, "How to license intangible property", Quarterly Journal of Economics 101, 567-589.

Muto, S., 1993, “On licensing policies in Bertrand competition”, Games and Economic Behavior 5, 257267.

Rockett, K., 1990, “The quality of licensed technology", International Journal of Industrial Organization $8,559-574$. 
Rostoker, M., 1984, A survey of corporate licensing, IDEA: The Journal of Law and Technology 24, 59-92.

Shapiro, C., 1985, "Patent licensing and R\&D rivalry", American Economic Review 75, 139-152.

Wang, X.H., 1998, "Fee versus royalty licensing in a Cournot duopoly model”, Economics Letters 60, 5562. 